Check for updates

Cite this: RSC Adv., 2019, 9, 16472

Received 28th March 2019 Accepted 21st May 2019

DOI: $10.1039 / c 9 r a 02364 j$

rsc.li/rsc-advances

\section{Highly stable binder free CNTs/rGO aerogel electrode for decolouration of methylene blue \& palm oil mill effluent via electro-Fenton oxidation process}

Muhammad Amirul Nazhif Mohd Nohan, ${ }^{a}$ Chin Hua Chia, (D) *a Aina Shasha Hashimi, Siew Xian Chin, ${ }^{\mathrm{b}}$ Poi Sim Khiew, ${ }^{\mathrm{c}}$ Sarani Zakaria, ${ }^{a}$ Azima Azmi, ${ }^{a}$ Kam Sheng Lau ${ }^{a}$ and Nur Fazlinda Razali ${ }^{a}$

In this study, single wall carbon nanotubes (CNTs)/reduced graphene oxides (rGO) aerogels were prepared by a one-pot hydrothermal process without using a binder. The produced CNTs/rGO aerogel was used as cathode in electro-Fenton system for the decolouration of methylene blue (MB) and palm oil mill effluent (POME). The addition of CNTs increased the surface area, pore volume and conductivity of the rGO aerogel, which further enhanced their performance as cathode towards the decolouration of MB and POME via electro-Fenton reaction. Complete decolouration of MB using rGO aerogel without CNTs could not be achieved. The effect of electro-Fenton reaction parameters conducted using the aerogel samples including, current, electrolyte concentrations and $\mathrm{pH}$, were investigated accordingly. The CNTs/rGO aerogel electrode also showed high stability and reusability for up to six consecutive treatment cycles for MB. Besides, the CNTs/rGO aerogel also showed good performance in treating POME with 69.8\%, 47.6\% and $58.1 \%$ of reduction in true colour, total organic carbon (TOC) and chemical oxygen demand (COD), respectively, via 60 minutes electro-Fenton reaction. This study showed that CNTs/rGO aerogels with high porosity and stability can be prepared using simple procedure without adding binder. This fully carbon-based aerogel can serve as effective cathode for decolouration of organic dye and effluent.

\section{Introduction}

Advanced oxidation processes (AOP) have been popular methods for wastewater treatment, including ozonation, UV treatment, physical AOP (ultrasound, microwave, electro beam) and catalyst AOP (photocatalyst, Fenton reaction) $\cdot^{1-6}$ ElectroFenton process is known as electrochemical advanced oxidation process (EAOP) with high efficiency in decomposition of destructing persistent organic pollutants by hydroxyl radicals $(\cdot \mathrm{OH}) .^{7,8}$ Hydrogen peroxide $\left(\mathrm{H}_{2} \mathrm{O}_{2}\right)$ is produced from the cathode of the electro-Fenton system which is subsequently reacted with ferrous ions $\left(\mathrm{Fe}^{2+}\right)$ to produce ${ }^{\circ} \mathrm{OH}$ as indicated in eqn $(1) \cdot{ }^{9-11}$

$$
\mathrm{H}_{2} \mathrm{O}_{2}+\mathrm{Fe}^{2+}+\mathrm{H}^{+} \rightarrow \cdot \mathrm{OH}+\mathrm{H}_{2} \mathrm{O}
$$

\footnotetext{
${ }^{a}$ Materials Science Program, Faculty of Science and Technology, Universiti Kebangsaan Malaysia, 43600 Bangi, Selangor, Malaysia. E-mail: chia@ukm.edu.my

${ }^{b}$ ASASIpintar Program, Pusat PERMATApintar, Universiti Kebangsaan Malaysia, 43600 Bangi, Selangor, Malaysia

${ }^{c}$ Center of Nanotechnology and Advanced Materials, Faculty of Engineering, University of Nottingham Malaysia Campus, Jalan Broga, 43500, Semenyih, Selangor, Malaysia
}

In situ generation of $\mathrm{H}_{2} \mathrm{O}_{2}$ is the core component for the production of ${ }^{\circ} \mathrm{OH}$ radicals in electro-Fenton process. ${ }^{11,12} \mathrm{H}_{2} \mathrm{O}_{2}$ is reactive and unstable. In situ generations of $\mathrm{H}_{2} \mathrm{O}_{2}$ eliminates the risk of transportation and storage of $\mathrm{H}_{2} \mathrm{O}_{2} \cdot{ }^{11,12} \mathrm{H}_{2} \mathrm{O}_{2}$ is produced at cathode involving two-electrons oxygen reduction reaction as indicated in eqn (3)., ${ }^{9,10}$ The efficiency of the $\mathrm{H}_{2} \mathrm{O}_{2}$ production is a key parameter of the electro-Fenton process.

$$
\mathrm{O}^{2}+2 \mathrm{H}^{+}+2 \mathrm{e}^{-} \rightarrow \mathrm{H}_{2} \mathrm{O}_{2}
$$

Hence, the improvement of cathode material to increase $\mathrm{H}_{2} \mathrm{O}_{2}$ production is of high importance for enhancing the efficiency of the electro-Fenton process. Carbonaceous materials, including graphite, ${ }^{13}$ carbon felt,,${ }^{14,15}$ carbon sponge,${ }^{16}$ carbon aerogel, ${ }^{17}$ and activated carbon fibre ${ }^{18,19}$ are among the widely studied cathode materials for electro-Fenton process due to their advantages such as good stability, high conductivity, low cost, non toxic and low catalytic activity for $\mathrm{H}_{2} \mathrm{O}_{2}$ decomposition. ${ }^{11}$ Besides, uses of polymer binder in the production of carbonaceous electrode is avoided as it can limit the performance by reducing the conductivity of electrode. ${ }^{20}$ Therefore the design on binder-free electrodes are established with the presence of CNTs to improve mechanical and electrical properties of the electrodes. ${ }^{21-24}$ 
In this study, reduced-graphene oxide (rGO) aerogel is produced and used as cathode material for electro-Fenton process. To further enhance the conductivity of the electrode, CNTs are added into the rGO as conductive filler to further enhance the conductivity properties of the electrode. The CNTs are treated by nitric acid before used. This is because CNTs has high hydrophobic characteristic and low wettability which limit the access of ions and presence of active site for electron transfer. Chemical treatment of CNTs can increase oxygencontaining functional groups (carboxylic acid, carbonyl and hydroxyl), which can increase accessible sites for free electrolytes ions and help in enhancing the homogeneity of CNTs in GO solution for the preparation of well-dispersed CNTs/rGO aerogel electrode. ${ }^{23,25}$ Aggregation of CNTs can occur when electrical repulsive forces are lower than the van der Waals force which are important to induce repulsion force for better CNTs dispersion. ${ }^{26}$ Besides, dispersion of CNTs is important for high electrode stability and conductivity, while the presence of GO can act as surfactant which can enhance the dispersion of CNTs. $^{27}$

The produced CNTs/rGO electrodes are further tested in the decolouration process of organic dye using an electro-Fenton system. Herein, few parameters are studied, such as CNTs loading, electric current intensity, $\mathrm{pH}$, and electrolyte concentration, for the optimization of the electro-Fenton process. The stability and reusability of the electrodes are also determined. To further evaluate the viability of the CNTs/rGO aerogel for real application, the aerogel was used to treat palm oil mil effluent (POME) using the optimum electro-Fenton condition for MB. The electro-Fenton performance was evaluated in terms of decolouration, reduction of total organic carbon (TOC) and chemical oxygen demand (COD).

\subsection{Materials and methods}

1.1.1 Materials. Carbon nanotubes (CNTs) (75\% purity, $<15 \%$ metal impurities). Graphite flakes (32461, 100 mesh $\geq 75 \%$ ), sodium sulfate $\left(\mathrm{Na}_{2} \mathrm{SO}_{4}\right)$, methylene blue (MB) hydrate and ferrous sulfate heptahydrate $\left(\mathrm{FeSO}_{4} \cdot 7 \mathrm{H}_{2} \mathrm{O}\right)$ were purchased from Sigma-Aldrich (St Louis, MO). Potassium permanganate $\left(\mathrm{KMnO}_{4}\right)$ (99 wt\% purity), sulfuric acid $\left(\mathrm{H}_{2} \mathrm{SO}_{4}\right)$ (98 wt\% purity), nitric acid $\left(\mathrm{HNO}_{3}\right)(65 \%)$ and hydrogen peroxide (30 wt \% purity) were purchased from Merck (Darmstadt, Germany). Ascorbic acid was purchased from R\&M Chemicals.

1.1.2 CNTs treatment. $2.5 \mathrm{~g}$ of raw CNTs was dispersed in deionized water using ultrasonication 3 minutes and then treated with nitric acid $(8.0 \mathrm{M})$ in a reflux system at room temperature. After that, the CNTs were washed several times by filtration using deionized water until it reaches $\mathrm{pH}$ 7. The washed CNTs were then dried in a vacuum oven at $80{ }^{\circ} \mathrm{C}$ overnight.

1.1.3 Preparation of CNTs/rGO aerogel. Graphene oxide (GO) was synthesized from the oxidation of graphite flakes using a modified Hummers method. ${ }^{28}$ To prepare aqueous dispersed CNTs/GO, CNTs (15 and $30 \mathrm{mg}$ ) was added into $20 \mathrm{ml}$ GO (50 mg) and homogenized by ultrasonication for 3 minutes. $0.15 \mathrm{~g}$ of ascorbic acid was added into the resulting CNTs/GO dispersion and stirred for 10 minutes using magnetic stirrer. Ascorbic acid acts as green reducing agent to reduce GO. ${ }^{29}$ The mixture was then transferred into an Teflon-lined autoclave and heated in an oven at $200{ }^{\circ} \mathrm{C}$ for 12 hours. The obtained CNTs/ rGO hydrogel underwent phase transfer by immersing in distilled water for 3 days to exchange former solution inside hydrogel, and followed by freeze-drying process to produce aerogel. The CNTs/rGO with $15 \mathrm{mg}$ and $30 \mathrm{mg}$ of CNTs content were denoted as 30\%-CNTs/rGO and 60\%CNTs/rGO respectively. rGO aerogel was also produced as the control sample. Fig. 1 summaries the overall fabrication procedure of CNTs/rGO hydrogel and aerogel.

1.1.4 Characterization of the rGO and CNTs-rGO aerogels. A beaker-type three-electrode cell was used to analyze electrochemical properties of the rGO and CNTs/rGO aerogels, in which platinum plate and $\mathrm{Ag} / \mathrm{AgCl}$ electrode were used as counter and reference electrode respectively. The working electrode consists of CNTs/rGO with different CNTs concentrations (15 and $30 \mathrm{mg}$ ). Cyclic voltammetry measurements were conducted using a Potentiostat/Galvanostat/ZRA (Reference 600 , Gamry Instrument). The morphology and structure of the aerogel samples were examined on a field-emission scanning electron microscopy (FESEM, Zeiss Merlin). Nitrogen adsorption/desorption isotherms were obtained at $77 \mathrm{~K}$ on an automated adsorption device (Micromeritic ASAP 2020) to measure the surface area of aerogel using the BrunauerEmmett-Teller (BET) method. Bulk resistance of the aerogels was measured using a multimeter (Victor VC890D).

1.1.5 Electro-Fenton oxidation experiments. ElectroFenton experiments were conducted in a $100 \mathrm{ml}$ beaker equipped with two electrodes that are totally immersed into the solution and filled with $50 \mathrm{ml}$ methylene blue (MB) solution. The experiment set up is shown in Fig. 2. CNTs/rGO aerogel $(1.5 \mathrm{~cm} \times 1 \mathrm{~cm})$ was used as cathode, while a platinum plate $(1.5 \mathrm{~cm} \times 1 \mathrm{~cm})$ was used as anode. The distance between cathode and anode was fixed at $1 \mathrm{~cm}$ and remained constant for all experiments. A magnetic stirrer was used to provide a continuous vigorous stirring of the solution. The solution was aerated for $10 \mathrm{~min}$ using an air pump prior to the reaction and continued to the end of experiment to maintain the dissolved oxygen content of the solution. $\mathrm{H}_{2} \mathrm{SO}_{4}$ was added to obtain the

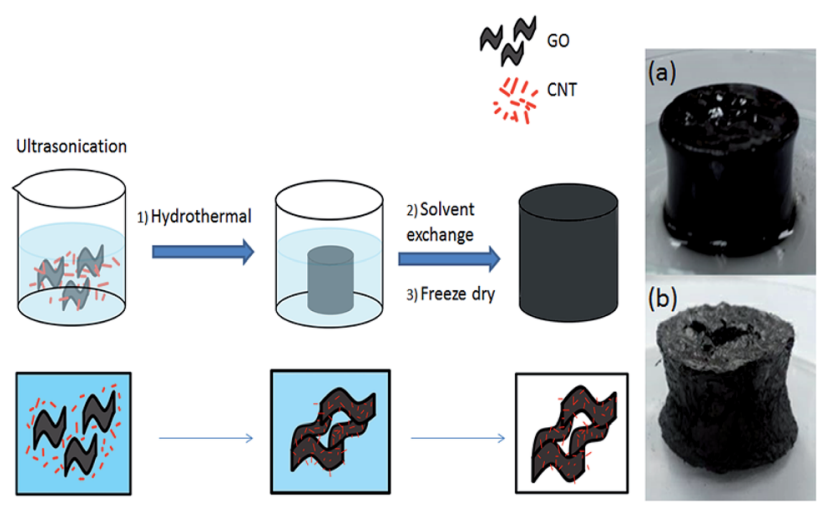

Fig. 1 Synthesis scheme for rGO and CNTs/rGO aerogels: (a) hydrogel and (b) aerogel. 


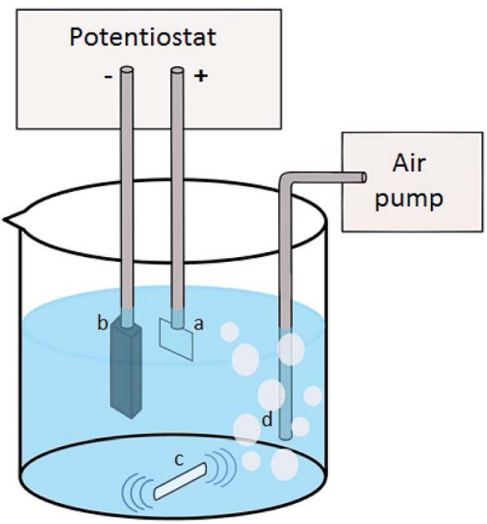

Fig. 2 Schematic diagram of electro Fenton reaction system: (a) anode, (b) cathode, (c) magnetic stirrer, and (d) aeration.

required $\mathrm{pH}$ before starting the electro-Fenton process. A certain quantity of $\mathrm{FeSO}_{4} \cdot 7 \mathrm{H}_{2} \mathrm{O}$ was added into the solution with the desired concentration. $\mathrm{Na}_{2} \mathrm{SO}_{4}$ was added to the solution with certain concentration to maintain the ionic strength and improve the conductivity of the medium. A potentiostat was connected to the electrodes and worked with a constant current. Besides MB, discolouration of palm oil mill effluent (POME) was also conducted using the CNTs/rGO aerogel by applying the optimum parameters obtained from the treatment of MB. The POME was filtered before used to remove suspended solids that might affect the efficiency of treatment.

1.1.6 Analytical procedure. The concentration of $\mathrm{MB}$ and true colour of POME were measured by taking aliquot samples $(1 \mathrm{ml})$ every 5 minutes and filtered using PTFE membrane (0.2 $\mu \mathrm{m})$ to remove any suspended materials before measurements using a UV-VIS spectrophotomter (Jenway, 7315) at $664 \mathrm{~nm}$ and a VIS spectrophotometer (Hach DR 3900) at $455 \mathrm{~nm}$, respectively. TOC and COD analyses were performed according to standard direct method (Method 10173) and USEPA reactor digestion method (Method 8000) respectively. The concentration of $\mathrm{H}_{2} \mathrm{O}_{2}$ generated during the electro-Fenton experiment was quantified by potassium permanganate titration method. ${ }^{30}$ Dissolved oxygen (DO) content of the MB solution was measured throughout the treatment process using a multimeter with luminescent/optical dissolve oxygen (LDO) probe (HQ30D).

\section{Results and discussion}

\subsection{Characterization of aerogels}

2.1.1 SEM and BET. The microstructure and morphology of the $\mathrm{rGO}$ and CNTs/rGO aerogels were observed under SEM. Fig. 3a shows that the rGO aerogel contains stacked graphene sheets with wrinkle-like structure. Wrinkle like structure of graphene sheets can provide high surface and increase active sites for the electron transfer for the generation of hydrogen peroxide. ${ }^{31}$ In Fig. 3c, wrapping of rGO sheets toward CNTs and interconnected rGO sheets by CNTs can be seen. With the entanglement between CNTs and rGO sheets, it can help in electron transfer and adsorption of electrolyte ions. According to SEM images in Fig. $3 \mathrm{~b}$ and d, the pore size of rGO aerogel is
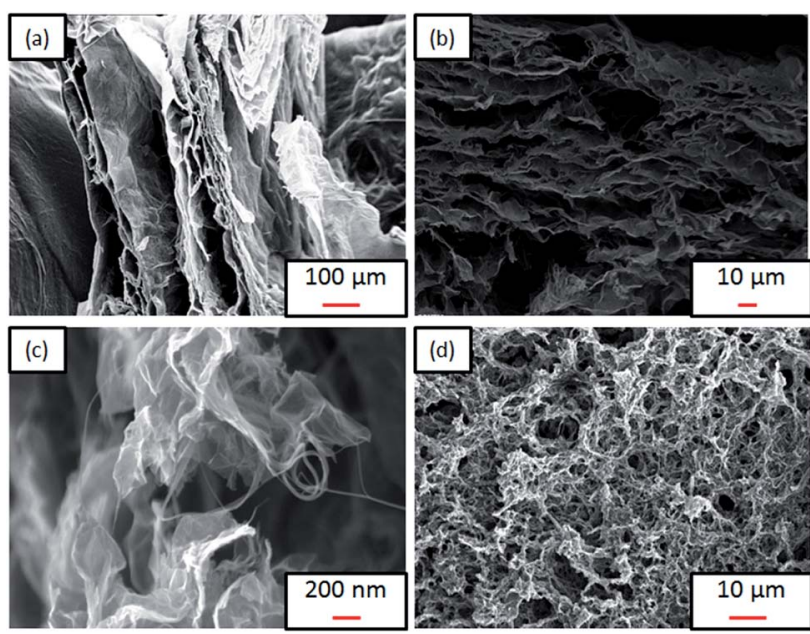

Fig. 3 FESEM images of (a) rGO surface, (b) rGO cross section, (c) $60 \mathrm{wt} \%$-CNTs/rGO surface, (d) $60 \mathrm{wt} \%$-CNTs/rGO cross section.

larger compared to $\mathrm{CNTs} / \mathrm{rGO}$ aerogel and entanglement of CNTs with rGO sheets can be clearly seen. The stacked structure of CNTs/rGO aerogel is considered more promising to be used as electrochemically active material compared to rGO aerogel by offering higher surface area and active sites for the generation of $\mathrm{H}_{2} \mathrm{O}_{2}$.

To further support findings obtained from the FESEM, surface area, pore volume and pore size of the aerogel samples were measured using BET analysis, as shown in Table 1. The presence of CNTs helps in increasing the surface area and active sites. $^{24,32}$

Due to the high roughness and porosity of the aerogel surfaces, bulk resistance was measured instead of sheet resistance. Bulk resistance of the rGO aerogel was decreased from approximately $20 \mathrm{k} \Omega$ to 40 and $18 \Omega$ with the addition of $30 \%$ and $60 \%$ CNTs, respectively. The high resistance of the rGO aerogel could be due to it high porous structure in which the rGO sheets are not well interconnected. The CNTs added have served as conductive pathway to interconnect the rGO sheets. It is interesting to note that the addition of CNTs not only has increased the BET surface area and pore volume of the aerogels, but it has also significantly enhanced the bulk conductivity of the aerogel.

2.1.2 Cyclic voltammetry. The cyclic voltammograms of the rGO and CNTs/rGO aerogels which were collected at the same scan rate of $10 \mathrm{mV} \mathrm{s}^{-1}$ are shown in Fig. 4 a. It could be seen that the $60 \%-\mathrm{CNTs} / \mathrm{rGO}$ aerogel yielded the highest current density and enlarged curve area as compared to the rGO and 30\%-CNTs/ rGO aerogels. Fig. $4 \mathrm{~b}$ shows that the increase in electrolyte

Table 1 BET surface area, pore volume and average pore size of $r G O$, $30 \%$-CNTs/rGO and $60 \%$-CNTs/rGO aerogels

\begin{tabular}{llll}
\hline Sample & $\begin{array}{l}\text { BET surface } \\
\text { area }\left(\mathrm{m}^{2} \mathrm{~g}^{-1}\right)\end{array}$ & $\begin{array}{l}\text { Pore volume } \\
\left(\mathrm{cm}^{3} \mathrm{~g}^{-1}\right)\end{array}$ & $\begin{array}{l}\text { Average pore } \\
(\AA)\end{array}$ \\
\hline rGO & 38.83 & 0.3487 & 649.0 \\
$30 \%-C N T s / \mathrm{rGO}$ & 156.7 & 0.678 & 381.1 \\
$60 \%-C N T s / \mathrm{rGO}$ & 256.9 & 1.302 & 169.8
\end{tabular}



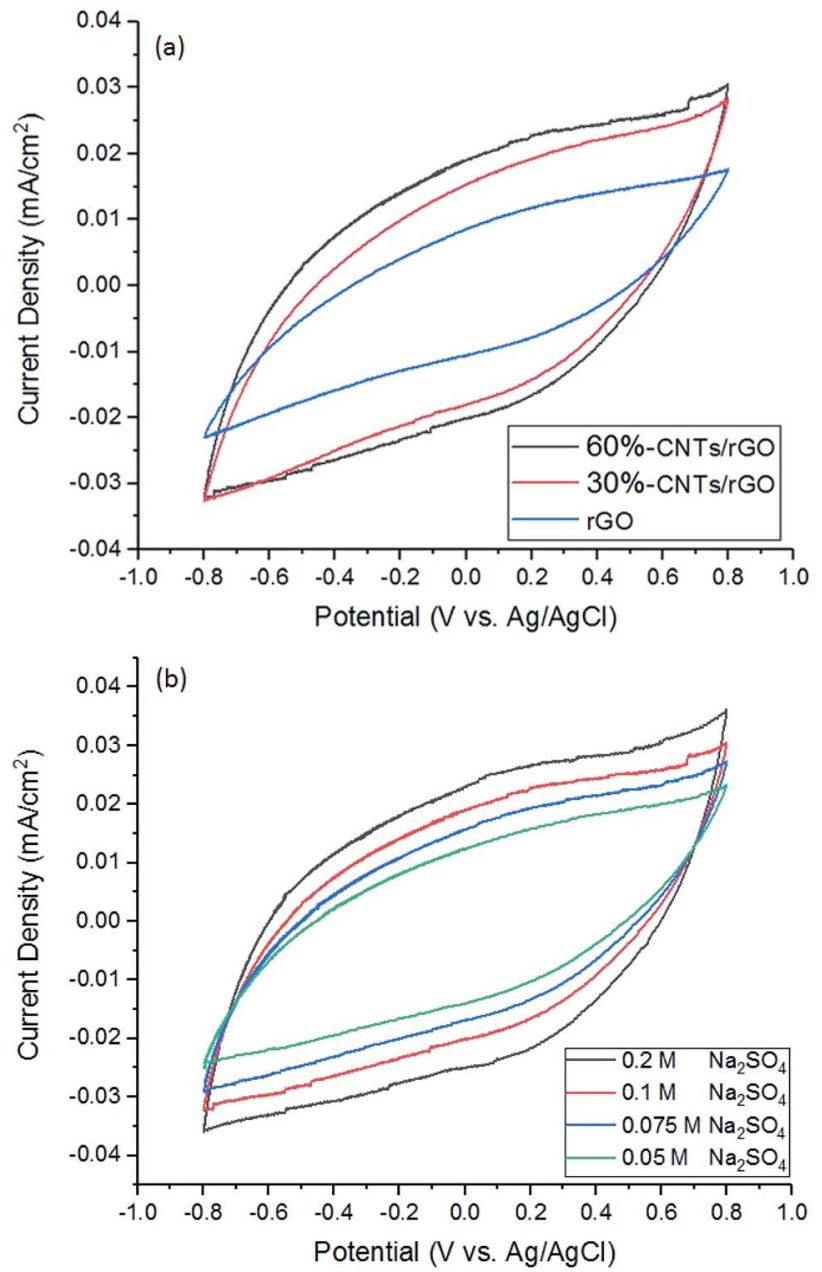

Fig. 4 (a) Comparison of the $\mathrm{CV}$ of $\mathrm{rGO}$ and $\mathrm{CNTs} / \mathrm{rGO}$ aerogels. Conditions: $\mathrm{pH}$ 3, current $80 \mathrm{~mA}, 0.1 \mathrm{M} \mathrm{Na}_{2} \mathrm{SO}_{4}$, (b) CV of $60 \%$-CNTs/ $\mathrm{rGO}$ aerogel with different electrolyte concentrations. Conditions: $\mathrm{pH}$ 3 , current $80 \mathrm{~mA}$ and $10 \mathrm{mV} \mathrm{s}^{-1}$.

concentration would result in improvement in solution conductivity and electron transfer.

2.1.3 Electrochemical impedance spectroscopy. Electrochemical impedance spectroscopy (EIS) analyses were carried out to understand better how CNTs affect the internal resistance of the rGO aerogel. Nyquist plots of the CNTs/rGO aerogel with different mass ratios of rGO to CNTs are shown in Fig. 5. The Nyquist spectra can be fitted with a modified Randles circuit. The resulting equivalent circuit parameters are listed in Table 2 . It can be seen that the introduction of CNTs, $30 \mathrm{wt} \%$ and $60 \mathrm{wt} \%$, has reduced the internal resistance (R1) of the rGO aerogel from $20.37 \mathrm{ohm}$ to 7.872 ohm and $7.154 \mathrm{ohm}$, respectively. This enhancement is consistent with the measurement of bulk resistance of the aerogels.

\subsection{Electro-Fenton reaction for decolouration of $\mathrm{MB}$}

2.2.1 CNT loadings. The dosage of the CNTs is important to enhance conductivity of the rGO aerogel which would increase efficiency of the electro-Fenton reaction. Fig. 6 shows that the decolouration of $\mathrm{MB}$ was enhanced with increase loading of CNTs. The decolouration performance of the aerogel samples

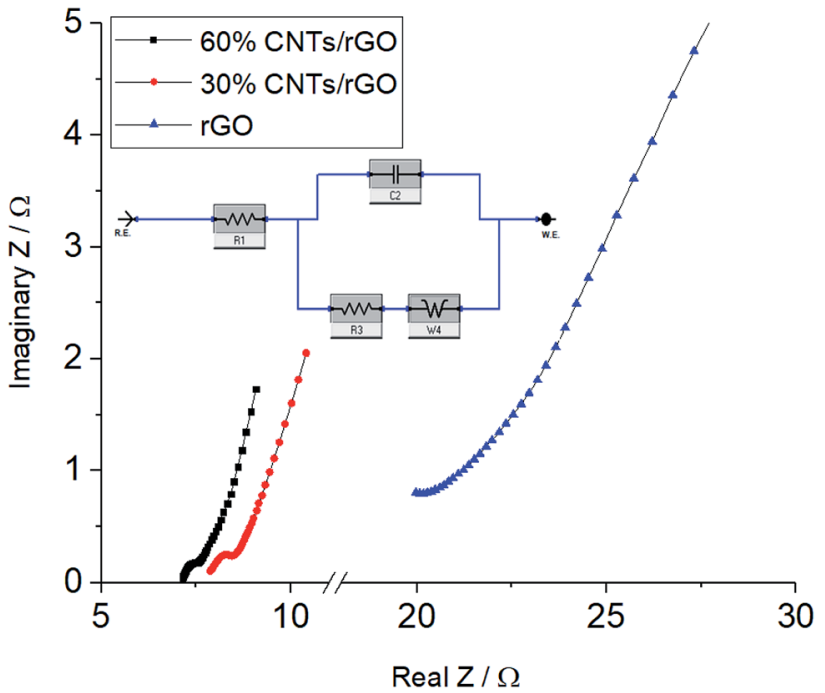

Fig. 5 Nyquist plots of CNTs/rGO composites with different mass ratios at $10 \mathrm{mV}$ (ac) superimposed on $0 \mathrm{~V}$ (dc) vs. $\mathrm{Ag} / \mathrm{AgCl}$ with frequencies ranged from $100 \mathrm{kHz}$ to $0.2 \mathrm{~Hz}$, measured in $0.1 \mathrm{M} \mathrm{Na}_{2} \mathrm{SO}_{4}$ solutions.

Table 2 Equivalent circuit parameters obtained from Nyquist plots by fitting

\begin{tabular}{lcll}
\hline Parameter & rGO & $30 \% \mathrm{CNTs} / \mathrm{rGO}$ & $60 \% \mathrm{CNTs} / \mathrm{rGO}$ \\
\hline$R_{1}(\mathrm{ohm})$ & 20.37 & 7.872 & 7.154 \\
$C_{2}(\mathrm{~F})$ & 0.000128 & 0.000546 & 0.00111 \\
$R_{3}(\mathrm{ohm})$ & 3.93 & 0.547 & 0.357 \\
$W_{4}\left(\mathrm{~S} \mathrm{~s}^{(-1 / 2)}\right)$ & 0.0254 & 0.311 & 0.376 \\
\hline
\end{tabular}

increased with the CNT content, in which the $60 \%$-CNTs/rGO aerogel exhibited the highest MB decolouration which can be due to the higher conductivity and surface area. Higher CNTs as a filler would lead to the higher and faster generation of ${ }^{\circ} \mathrm{OH}$

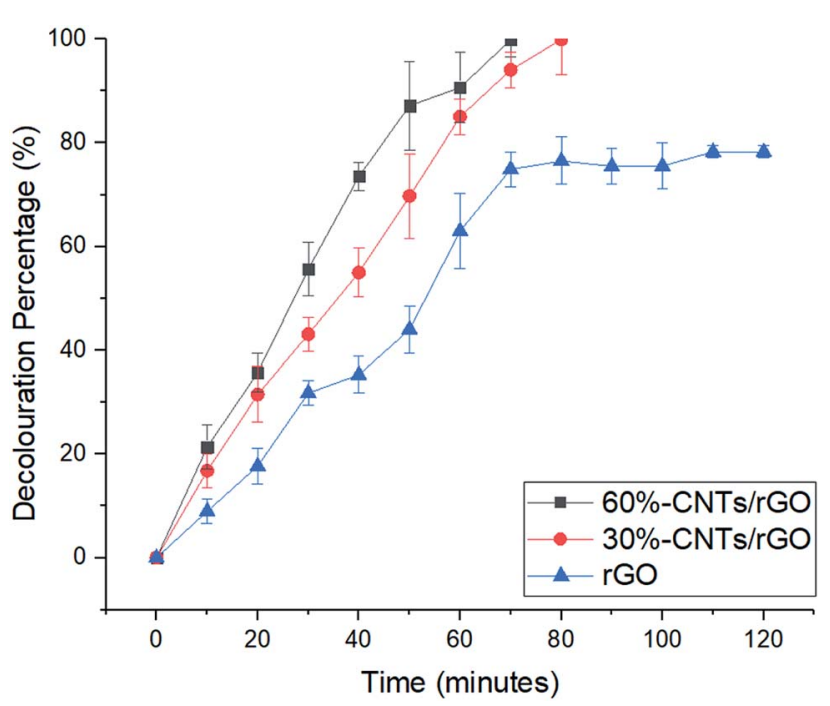

Fig. 6 Decolouration of methylene blue in the electro Fenton system with different CNTs concentration as rGO electrode filler. Conditions: $\mathrm{pH} 3$, current $80 \mathrm{~mA}$ and $0.1 \mathrm{M} \mathrm{Na}_{2} \mathrm{SO}_{4}$. 
which was resulted from the increase of active site, surface area and conductivity.

As the reaction proceeds, $\mathrm{MB}$ colour faded indicate decrease of MB concentration. This can be described from collapse of MB molecule structure or chromoforic destruction. Decomposition of $\mathrm{H}_{2} \mathrm{O}_{2}$ plays a vital role in the generation of ${ }^{\circ} \mathrm{OH}$ radicals which are the main oxidizing agent of $\mathrm{MB}$ solution. The decomposition of $\mathrm{MB}$ which can be described by the breaking of the $\mathrm{N}-$ $\mathrm{CH}_{3}, \mathrm{C}-\mathrm{N}, \mathrm{C}-\mathrm{S}$ and $\mathrm{CH}_{3}$ bonds to form intermediates that will be further oxidized into form $\mathrm{CO}_{2}, \mathrm{H}_{2} \mathrm{O}, \mathrm{Cl}^{-}, \mathrm{SO}_{4}{ }^{-}$and $\mathrm{NO}_{3}{ }^{-} .^{33}$

2.2.2 pH. The $\mathrm{pH}$ of solution is well known as an important factor in Fenton reaction. Acidic medium was preferred as basic pH adversely affects the overall treatment efficiency. ${ }^{34}$ In acidic medium, more protons are available in the solution that can promote the conversion of dissolving oxygen into $\mathrm{H}_{2} \mathrm{O}_{2} \cdot{ }^{35}$ As shown in Fig. 7, pH 3 gives 100\% decolouration in 60 minutes of treatment as compared to $\mathrm{pH} 5$ and 7 which did not achieve $100 \%$ decolouration and have reached a plateau at 80 and 90 minutes, respectively. At high $\mathrm{pH}, \mathrm{Fe}^{3+}$ ions would precipitate to form amorphous $\mathrm{Fe}(\mathrm{OH})_{3}$ and deposit on the electrode surface, resulting in less $\mathrm{Fe}^{2+}$ to be regenerated for Fenton reaction. ${ }^{36}$

2.2.3 Current density. Applied current density acts as the driving force of electron transfer and corresponds to the rate of $\mathrm{H}_{2} \mathrm{O}_{2}$ generation in electro-Fenton system. ${ }^{37}$ Fig. 8 shows that the greater the current applied, the higher the rate of $\mathrm{MB}$ decolouration. The increase in current not only helped in the production of ${ }^{\circ} \mathrm{OH}$ radicals, but also increase the regeneration rate of $\mathrm{Fe}^{2+}$ from $\mathrm{Fe}^{3+}$, resulting in higher efficiency of Fenton reaction. ${ }^{36}$

2.2.4 Electrolyte concentration. Fig. 9 shows the effect of $\mathrm{Na}_{2} \mathrm{SO}_{4}$ concentration on the decolouration performance of the $60 \%$-CNTs/rGO aerogel. In general, higher $\mathrm{Na}_{2} \mathrm{SO}_{4}$ favored the decoloration of $\mathrm{MB}$. From Fig. 4b, $0.2 \mathrm{M} \mathrm{Na}_{2} \mathrm{SO}_{4}$ gives higher current density compared to $0.1 \mathrm{M} \mathrm{Na}_{2} \mathrm{SO}_{4}$. However, $0.1 \mathrm{M}$ $\mathrm{Na}_{2} \mathrm{SO}_{4}$ was chosen as the optimum condition as there is not much different in term of the decoloration rate for $0.1 \mathrm{M}$ and

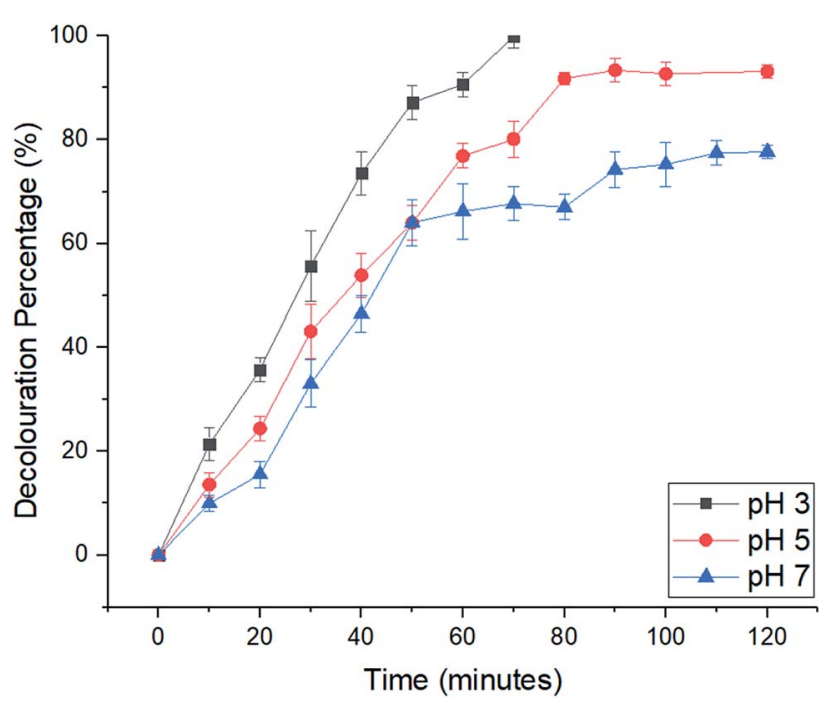

Fig. 7 Effect of different $\mathrm{pH}$ on decolouration of MB using $60 \%$-CNTs/ rGO aerogel as electrode. Conditions: current $80 \mathrm{~mA}$ and $0.1 \mathrm{M}$ $\mathrm{Na}_{2} \mathrm{SO}_{4}$.

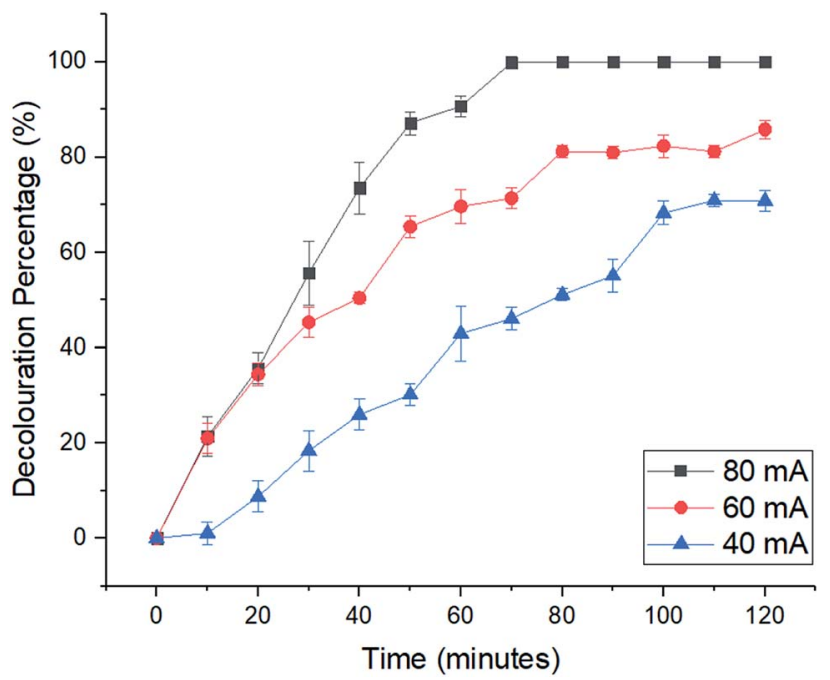

Fig. 8 Effect of different current on decolouration of MB using $60 \%$ CNTs/rGO aerogel. Conditions: $\mathrm{pH} 3$ and $0.1 \mathrm{M} \mathrm{Na}_{2} \mathrm{SO}_{4}$.

$0.2 \mathrm{M}$ of $\mathrm{Na}_{2} \mathrm{SO}_{4}$. Besides, the presence of excess sulphate might cause scavenging effect to hydroxyl radicals which would lower the treatment efficiency although $0.2 \mathrm{M} \mathrm{Na}_{2} \mathrm{SO}_{4}$ gives a better current density. ${ }^{37}$ Lower decolouration efficiency using $0.075 \mathrm{M}$ and $0.05 \mathrm{M} \mathrm{Na}_{2} \mathrm{SO}_{4}$ may be due to the insufficient conductivity of the solution for the electron transfer.

2.2.5 $\quad \mathrm{H}_{2} \mathrm{O}_{2}$ generation vs. dissolved oxygen content. Fig. 10 shows the relationship between $\mathrm{H}_{2} \mathrm{O}_{2}$ generated and the dissolved oxygen content under optimum electro-Fenton reaction parameters using the $60 \%$-CNTs/rGO aerogel. The $\mathrm{H}_{2} \mathrm{O}_{2}$ concentration increased linearly up to 80 minutes reached a plateau over time with the decrease of DO content from $8.19 \mathrm{mg} \mathrm{L}^{-1}$ to $6.47 \mathrm{mg} \mathrm{\textrm {L } ^ { - 1 }}$ at 20 minutes. The significant decrease in DO content at the first 20 minutes of reaction suggests the necessity of oxygen for the generation of $\mathrm{H}_{2} \mathrm{O}_{2}$. No further increase in DO content although the aeration was

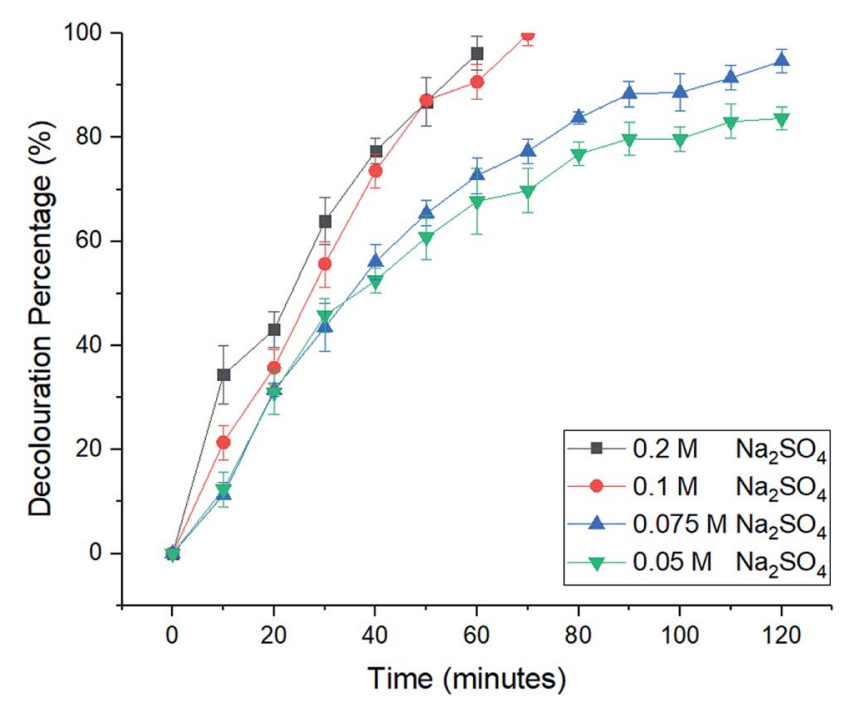

Fig. 9 Effect of different electrolyte concentrations on decolouration of $\mathrm{MB}$ using $60 \% \mathrm{CNTs} / \mathrm{rGO}$ aerogel. Conditions: $\mathrm{pH} 3$ and current 80 $m A$. 


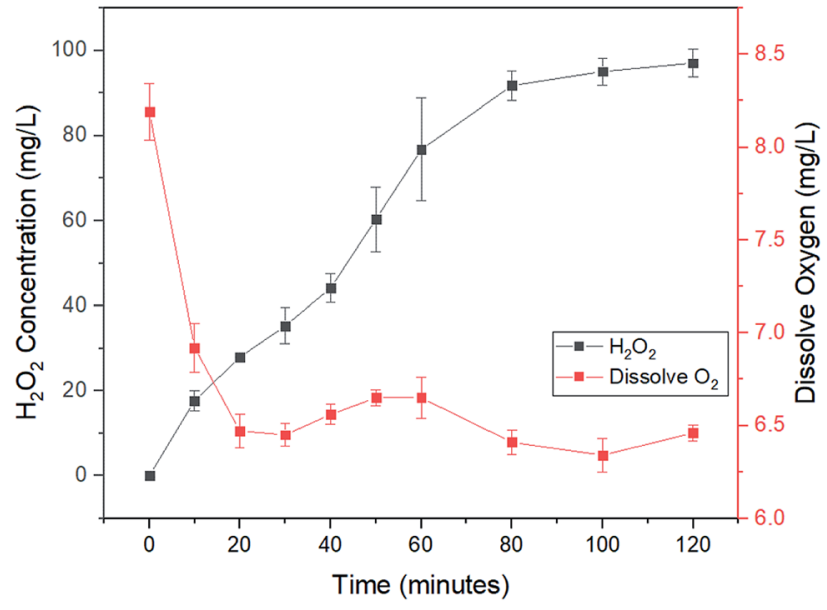

Fig. $10 \quad \mathrm{H}_{2} \mathrm{O}_{2}$ generation on electro Fenton system using $60 \%$-CNTs/ rGO aerogel. Conditions: $\mathrm{pH} 3$, current $80 \mathrm{~mA}$ and $0.1 \mathrm{M} \mathrm{Na}_{2} \mathrm{SO}_{4}$.

continuously performed, suggesting that the oxygen supplied has been consumed by the electro-Fenton process.

2.2.6 Reusability lability of $\mathrm{CNTs} / \mathrm{rGO}$ aerogel electrode. From an practical application perspective, electrode stability must be considered. The reusability of electrodes was evaluated by conducting six consecutive cycles of MB treatment (see Fig. 11). It can be seen that the decolouration performance of the $60 \%$-CNTs/rGO aerogel was maintained at $80 \%$ after the six consecutive runs. The $30 \%$-CNTs/rGO shows lower efficiency in decolouration for the consecutive treatment cycles, which can be attributed to the lower conductivity of the aerogel. Breakdown of rGO electrode occurred right after the first treatment cycle as the result of weak bonding between the rGO sheets. This observation further proven that the addition of CNTs can significantly improve mechanical stability and reusability of the aerogels.

2.2.7 Electro-Fenton reaction for decolouration of POME. Fig. 12 shows the decoloration of POME using $60 \%$-CNTs/rGO

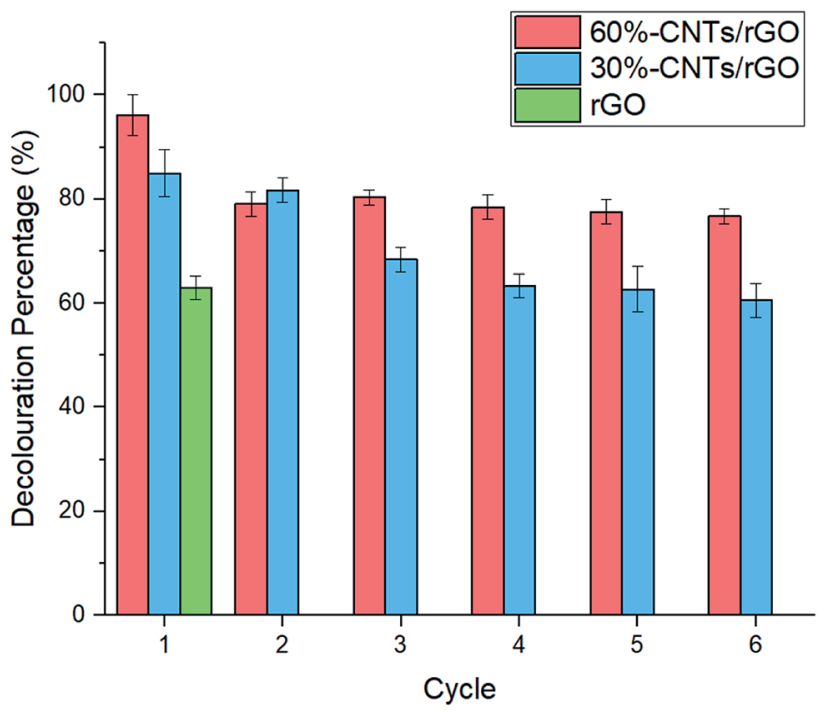

Fig. 11 Reusability tests for electro-Fenton decolouration of MB using rGO, 30\%-CNTs/rGO and 60\%-CNTs/rGO aerogels. Conditions: $\mathrm{pH} 3$, current $80 \mathrm{~mA}$, and $0.1 \mathrm{M} \mathrm{Na}_{2} \mathrm{SO}_{4}$.
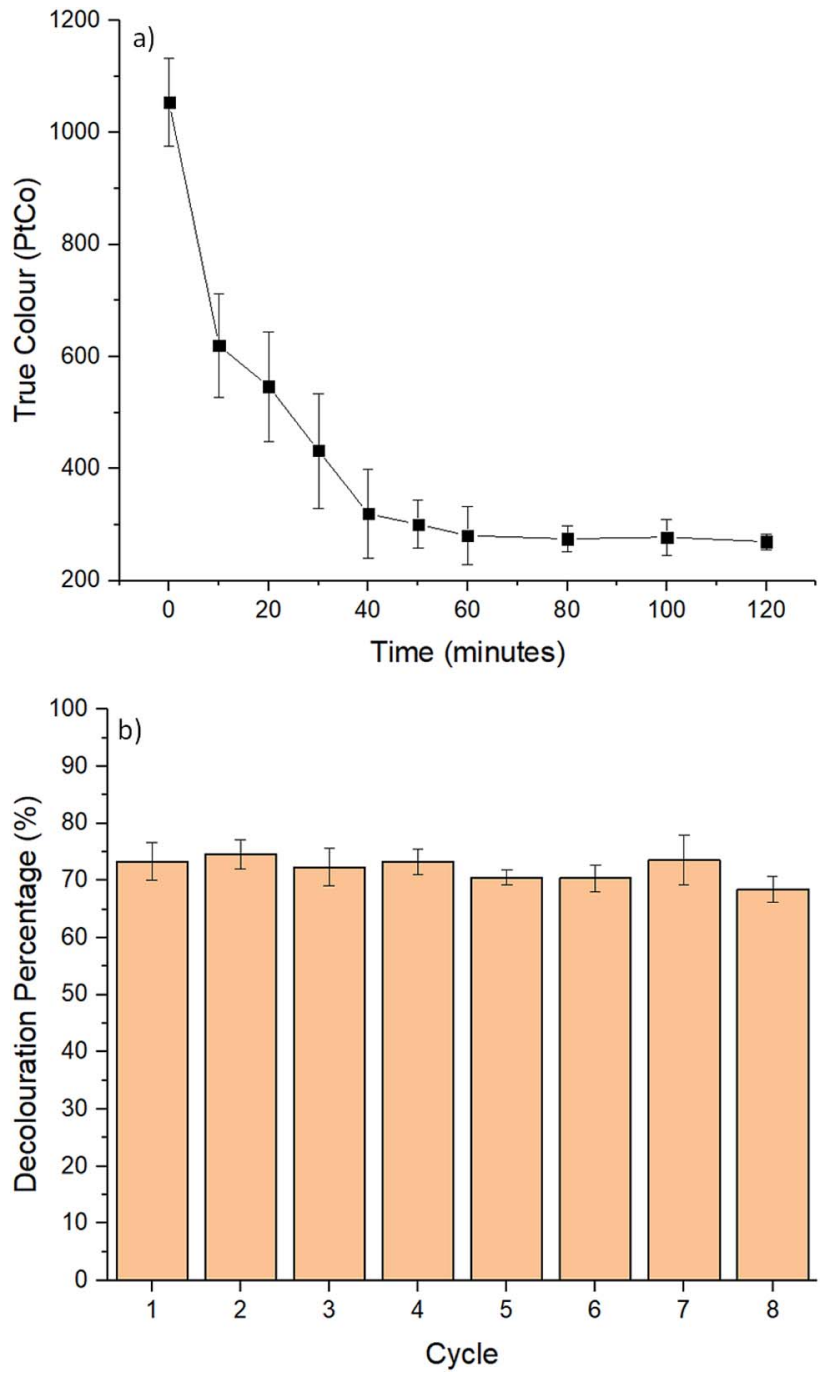

Fig. 12 Treatment of POME using $60 \%$-CNTs/rGO aerogel. (a) Decolouration of POME and (b) reusability test for electro-Fenton decolouration of POME. Conditions: $\mathrm{pH} 3$, current $80 \mathrm{~mA}$, and $0.1 \mathrm{M}$ $\mathrm{Na}_{2} \mathrm{SO}_{4}$, and 60 minutes for each cycle.

aerogel. Fig. 12a shows the decolouration of POME using the $60 \%$-CNTs/rGO aerogel conducted using the optimum parameters obtained from the experiments on $\mathrm{MB}$, i.e., $\mathrm{pH} 3,80 \mathrm{~mA}$, and $0.1 \mathrm{M} \mathrm{Na}_{2} \mathrm{SO}_{4}$. After 40 minutes of treatment, colour intensity (PtCo) of the POME was reduced from 1054 to 320 PtCo, which is equivalent to approximately $70 \%$ of decolouration. Fig. 12b shows that decolouration capability of the aerogel was maintained around $70 \%$ after eight consecutive treatment runs which was on par with the initial run which is at $73.34 \%$ of

Table 3 Total organic carbon (TOC) and chemical oxygen demand (COD) of POME before and after treatment using 60\%-CNTs/rGO aerogel via electro-Fenton reaction. Conditions: $\mathrm{pH} 3$, current $80 \mathrm{~mA}$, $0.1 \mathrm{M} \mathrm{Na}_{2} \mathrm{SO}_{4}$

\begin{tabular}{llll}
\hline & Initial $\left(\mathrm{mg} \mathrm{L}^{-1}\right)$ & Final $\left(\mathrm{mg} \mathrm{L}^{-1}\right)$ & Percentage removal (\%) \\
\hline TOC & 105 & 44 & 47.6 \\
COD & 401 & 210 & 58.1
\end{tabular}


POME decolouration, indicating the good reusability of the aerogel.

Table 3 presents the results of TOC and COD of POME before and after the electro-Fenton reaction. TOC and COD of the POME was reduced $47.63 \%$ and $58.1 \%$ respectively after 60 minutes of electro-Fenton reaction using the $60 \%$-CNTs/rGO aerogel electrode. The decrease in TOC was caused by demineralization of dissolved organic compounds in the POME water and carbon dioxide by ${ }^{\circ} \mathrm{OH}$ radicals generated.

\section{Conclusions}

This study described the preparation and utilization of CNTs/ rGO aerogel as a electrode for electro-Fenton reaction. The $60 \%$-CNTs/rGO aerogel showed good decolouration performance towards MB and POME as compared to the neat rGO due to its high surface area, porosity and bulk conductivity. It is also found that the $60 \%$-CNTs/rGO aerogel can be reused for more than six cycles of electro-Fenton reaction to decolorize MB and POME without significant reduction in performance.

\section{Conflicts of interest}

There are no conflicts of interest to declare.

\section{Acknowledgements}

The authors would like to thank the Centre of Research and Instrumentation (CRIM), UKM for the research grant GUP-2018159 provided.

\section{Notes and references}

1 D. Kanakaraju, B. D. Glass and M. Oelgem, J. Environ. Manag., 2018, 219, 189-207.

2 D. B. Miklos, C. Remy, M. Jekel, K. G. Linden and J. E. Drewes, Water Res., 2018, 139, 118-131.

3 Y. Lin, S. Wu, C. Yang, M. Chen and X. Li, Appl. Catal., B, 2019, 245, 71-86.

4 Y. Lin, S. Wu, X. Li, X. Wu, C. Yang, G. Zeng, Y. Peng, Q. Zhou and L. Lu, Appl. Catal., B, 2018, 227, 557-570.

5 S. Wu, H. Li, X. Li, H. He and C. Yang, Chem. Eng. J., 2018, 353, 533-541.

6 S. Wu, H. He, X. Li, C. Yang, G. Zeng, B. Wu, S. He and L. Lu, Chem. Eng. J., 2018, 341, 126-136.

7 Q. Wang, S. Zhou, S. Xiao, F. Wei, X. Zhao, J. Qu and H. Wang, RSC Adv., 2018, 8, 14775-14786.

8 X. Wang, K. Zhu, X. Ma, Z. Sun and X. Hu, RSC Adv., 2018, 8, 19971-19978.

9 Q. Peng, Z. Zhang, Z. Huang, W. Ren and J. Sun, RSC Adv., 2014, 4, 60168-60175.

10 L. Bounab, O. Iglesias, E. González-Romero, M. Pazos and M. Ángeles Sanromán, RSC Adv., 2015, 5, 31049-31056.

11 S. Qiu, L. Yu, D. Tang, W. Ren, K. Chen and J. Sun, Ind. Eng. Chem. Res., 2018, 57, 4907-4915.

12 B. Hou, B. Ren, R. Deng, G. Zhu, Z. Wang and Z. Li, RSC Adv., 2017, 7, 15455-15462.
13 T. X. H. Le, T. Van Nguyen, Z. Amadou Yacouba, L. Zoungrana, F. Avril, D. L. Nguyen, E. Petit, J. Mendret, V. Bonniol, M. Bechelany, S. Lacour, G. Lesage and M. Cretin, Chemosphere, 2017, 172, 1-9.

14 C. Zhang, M. Zhou, G. Ren, X. Yu, L. Ma, J. Yang and F. Yu, Water Res., 2015, 70, 414-424.

15 Y. Wang, Y. Liu, K. Wang, S. Song, P. Tsiakaras and H. Liu, Appl. Catal., B, 2015, 165, 360-368.

16 S. O. Ganiyu, T. X. Huong Le, M. Bechelany, G. Esposito, E. D. Van Hullebusch, M. A. Oturan and M. Cretin, J. Mater. Chem. A, 2017, 5, 3655-3666.

17 W. Ren, Q. Peng, Z. Huang, Z. Zhang, W. Zhan, K. Lv and J. Sun, Ind. Eng. Chem. Res., 2015, 54, 8492-8499.

18 H. Zhao, L. Qian, X. Guan, D. Wu and G. Zhao, Environ. Sci. Technol., 2016, 50, 5225-5233.

19 J. Hu, J. Sun, J. Yan, K. Lv, C. Zhong, K. Deng and J. Li, Electrochem. Commun., 2013, 28, 67-70.

20 X. Wang, W. Guo, Y. Zhu, X. Liang, F. Wang and P. Peng, Appl. Sci., 2018, 8, 2101.

21 J. H. Kim, J. Y. Hwang, H. R. Hwang, H. S. Kim, J. H. Lee, J. W. Seo, U. S. Shin and S. H. Lee, Sci. Rep., 2018, 8, 1-11.

22 F. Schütt, S. Signetti, H. Krüger, S. Röder, D. Smazna, S. Kaps, S. N. Gorb, Y. K. Mishra, N. M. Pugno and R. Adelung, Nat. Commun., 2017, 8, 1-10.

23 S. A. Shamsuddin, M. N. Derman, U. Hashim, M. Kashif, T. Adam, N. H. A. Halim and M. F. M. Tahir, AIP Conf. Proc., 2016, 1756, 090002.

24 Q. Yang, S. K. Pang and K. C. Yung, J. Power Sources, 2016, 311, 144-152.

25 J. Shen, A. Liu, Y. Tu, G. Foo, C. Yeo, M. B. Chan-Park, R. Jiang and Y. Chen, Energy Environ. Sci., 2011, 4, 42204229.

26 H. He, Y. Cheng, C. Yang, G. Zeng, C. Zhu and Z. Yan, J. Environ. Sci., 2017, 54, 135-141.

27 M. N. Mohd Zubir, A. Badarudin, S. N. Kazi, H. Nay Ming, R. Sadri and A. Amiri, J. Dispersion Sci. Technol., 2016, 37, 1395-1407.

28 N. M. Huang, H. N. Lim, C. H. Chia, M. A. Yarmo and M. T. Muhammad, Int. J. Nanomed., 2011, 6, 3443-3448.

29 S. Pei and H. M. Cheng, Carbon, 2012, 50, 3210-3228.

30 M. Bowman, J. Chem. Educ., 1949, 1, 103-104.

31 W. Yang, Y. Chen, J. Wang, T. Peng, J. Xu, B. Yang and

K. Tang, Nanoscale Res. Lett., 2018, 13, 181.

32 B. Hashwan, S. Saeed, M. F. Fatin, A. R. Ruslinda, M. K. Md Arshad, U. Hashim and R. M. Ayub, Appl. Mech. Mater., 2015, 754-755, 1156-1160.

33 Q. Wang, S. Tian, J. Cun and P. Ning, Desalin. Water Treat., 2013, 51, 5821-5830.

34 A. Babuponnusami and K. Muthukumar, International Journal of Advance Innovations, Thoughts \& Ideas, 2017, 3, 439-451.

35 E. Alfaya, O. Iglesias, M. Pazos and M. A. Sanromán, $R S C$ Adv., 2015, 5, 14416-14424.

36 M. Radwan, M. Gar Alalm and H. Eletriby, Journal of Water Process Engineering, 2018, 22, 155-162.

37 H. He and Z. Zhou, Crit. Rev. Environ. Sci. Technol., 2017, 132. 